\title{
MELHORIAS NO SISTEMA DE CONTROLE DE TEMPERATURA DE BOBINAMENTO*
}

Guilherme Monteiro Garcia ${ }^{1}$

\section{Resumo}

O resfriamento contínuo de forma controlada garante propriedades mecânicas específicas nos aços. Este trabalho apresenta melhorias feitas em um sistema de controle de resfriamento em um laminador de tiras a quente. As melhorias apresentadas garantiram uma melhora na performance de $\mathbf{5 \%}$ de forma a reduzir drasticamente o custo da não qualidade. As modificações visaram adaptar o sistema para uma nova realidade de grandes acelerações e desacelerações da tira no trem acabador visto o aumento da produtividade e a redução do uso da coil box.

Palavras-chave: Temperatura de bobinamento; Resfriamento laminar; Controle automático.

\section{IMPROVEMENTS IN COILING TEMPERATURE CONTROL SYSTEM}

\begin{abstract}
The continuous controlled cooling of strips ensures specific mechanical properties for steels. This paper presents improvements made in a cooling control system in a hot strip mill. The improvements presented brought an increase of $5 \%$ in performance, in order to drastic reduce the cost of non-quality. The changes aimed to adapt the system to a new reality of power accelerations and decelerations of the strip in the finishing mill due to an increasing productivity and reduced coil box use.

Keywords: Coiling temperature; Laminar flow; Automatic control.
\end{abstract}

1 Mestre em Engenharia Eletrônica e Computação, Especialista em Automação, ArcelorMittal Tubarão, Serra, Espírito Santo - Brasil. 


\section{INTRODUÇÃO}

As propriedades metalúrgicas de bobinas laminadas a quente possuem uma considerável importância. As transformações de fase dos aços, que garantem propriedades mecânicas específicas, são alcançadas graças ao resfriamento contínuo da tira de forma controlada. As condições para um devido controle de resfriamento são uma correta predição do volume de água necessário para atingir a temperatura de bobinamento desejada, assim como uma rápida resposta do controlador á perturbações durante a laminação (mudanças de velocidade, desvios de espessura e desvios na temperatura de acabamento).

Técnicas clássicas de controle não são suficientes para evitar o desvio da temperatura de bobinamento quando há perturbações durante a laminação. A principal perturbação para o resfriamento controlado é a mudança rápida de velocidade, seja acelerando ou desacelerando a tira no trem acabador. O tempo de reação dos atuadores finais torna impeditivo o simples controle por compensação do erro, de forma que a correta predição da temperatura de bobinamento, dado os valores de entrada, é necessária para antecipar a ação do controle.

Este trabalho apresenta melhorias feitas em um sistema de controle de resfriamento em um laminador de tiras a quente. As melhorias apresentadas garantiram uma melhora na performance de $5 \%$ de forma a reduzir drasticamente o custo da não qualidade.

No capítulo 2 será apresentado o princípio de funcionamento do sistema de resfriamento da ArcelorMittal Tubarão. No capítulo 3 serão descritos os principais problemas. No capítulo 4 serão descritos os resultados alcançados após as modificações propostas e finalizado uma conclusão do trabalho será apresentada no capítulo 5.

\section{SISTEMA DE RESFRIAMENTO LAMINAR DE TIRAS}

O sistema de resfriamento laminar de tiras tem a função de controlar o perfil da temperatura das tiras entre o trem acabador e a bobinadeira (ver Fig. 1). O objetivo é manter uma temperatura de bobinamento constante em todo o comprimento da tira.

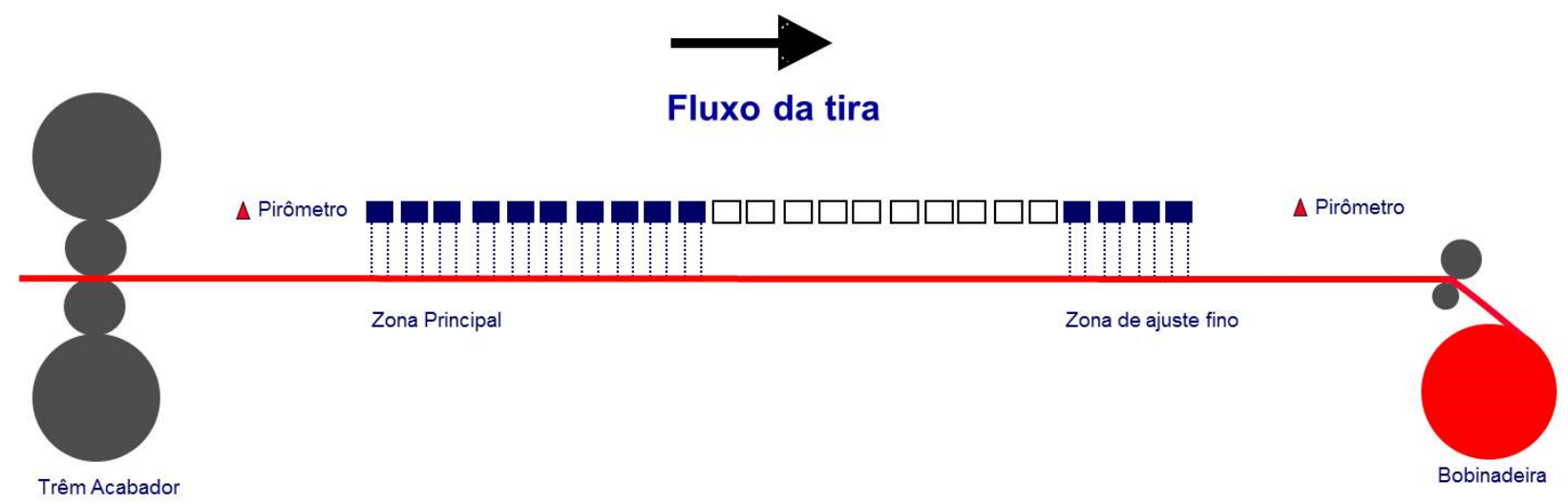

Figura 1. Sistema de resfriamento laminar de tiras.

Um modelo matemático calcula o volume de água necessário baseado na composição química, nas dimensões (largura e espessura), na velocidade da tira, na temperatura de acabamento (temperatura com que a tira irá sair do trem acabador) e na temperatura de bobinamento que se quer atingir. Essa quantidade de água é 
então distribuída nos chuveiros da zona principal seguindo uma estratégia prédefinida de resfriamento.

As estratégias de resfriamento são necessárias para diferenciar a taxa de resfriamento, ou simplesmente, o tempo gasto para sair da temperatura de acabamento e chegar na temperatura de bobinamento. O gráfico da figura 2 mostra diferentes estratégias de resfriamento existentes.

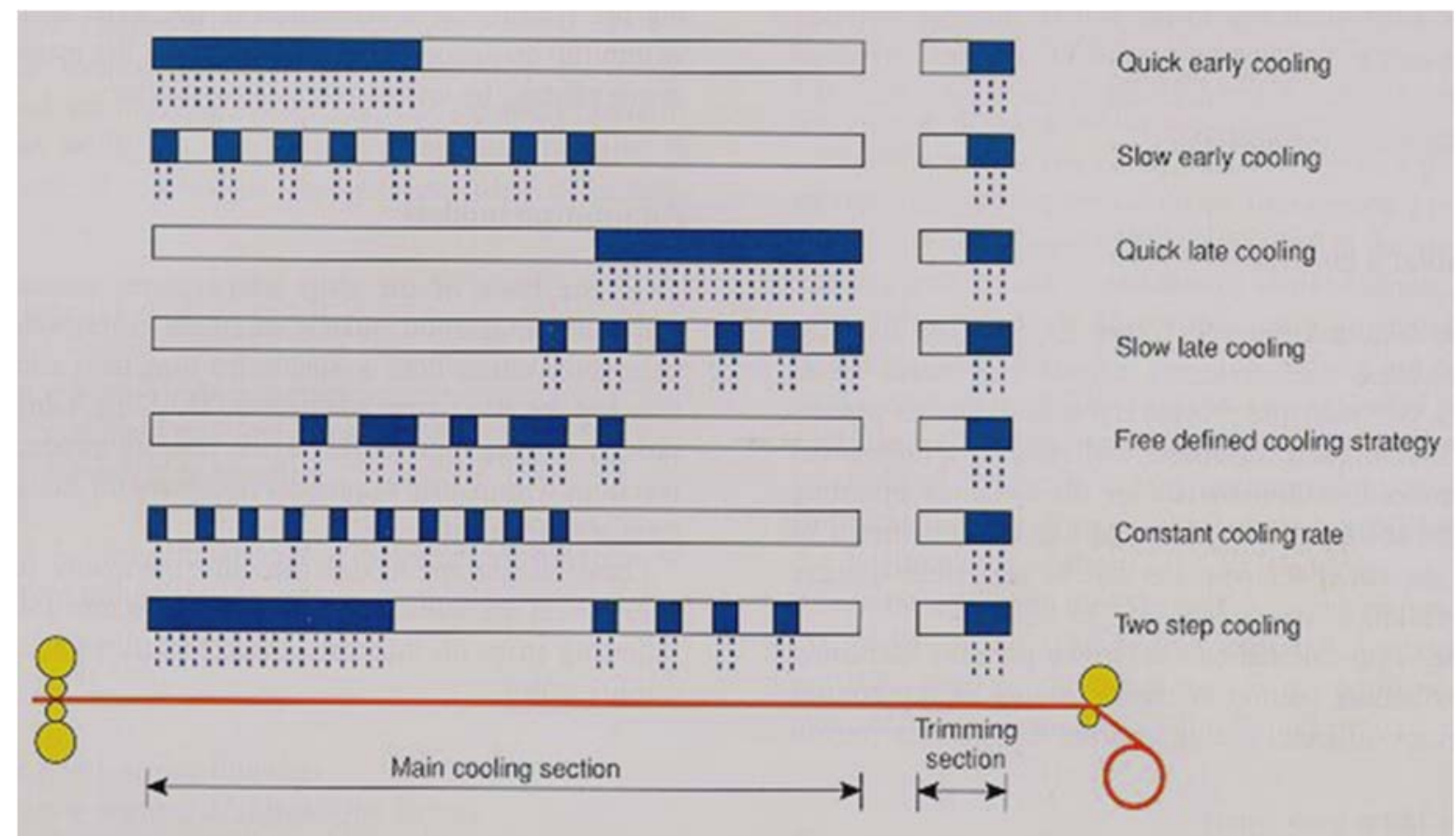

Figura 2. Sistema de resfriamento laminar de tiras.

Além da predição do volume de água pelo modelo matemático que é recalculado a cada 2 s o sistema possui um controle integral que compensa os eventuais distúrbios detectados na medição da temperatura de bobinamento. Assim como é responsável por rastrear a tira na mesa de resfriamento de forma a antecipar a abertura dos chuveiros antes da tira entrar na mesa e desligar os mesmo ao final do bobinamento da tira.

\section{QUEDA NA PERFORMANCE}

Até o ano de 2012 o acerto médio da temperatura de bobinamento entre $\pm 20^{\circ} \mathrm{C}$ era de $90 \%$, um índice muito bom e de acordo com o grande uso de coil box (aproximadamente $70 \%$ conforme Figura 3). Em 2013, devido ao aumento da produção, foi decidido diminuir gradualmente a utilização da coil box sendo necessário a partir de então uma maior aceleração da tira no trem acabador. Isso acarretou em uma queda brusca do acerto de temperatura passando para cerca de $80 \%$ enquanto o uso da coil box diminuiu para $50 \%$ das tiras.

A queda da performance concentrou-se nas tiras que passaram a ser laminadas sem o uso da coil box, uma vez que tanto o modelo matemático de predição quanto o controle de compensação do erro não foram projetados para este novo comportamento do sistema, tendo que responder a bruscas mudanças de velocidade e a altas vazões de água. 


\section{Acerto da Temperatura de Bobinamento em}

\section{$\pm 20^{\circ} \mathrm{C}$}

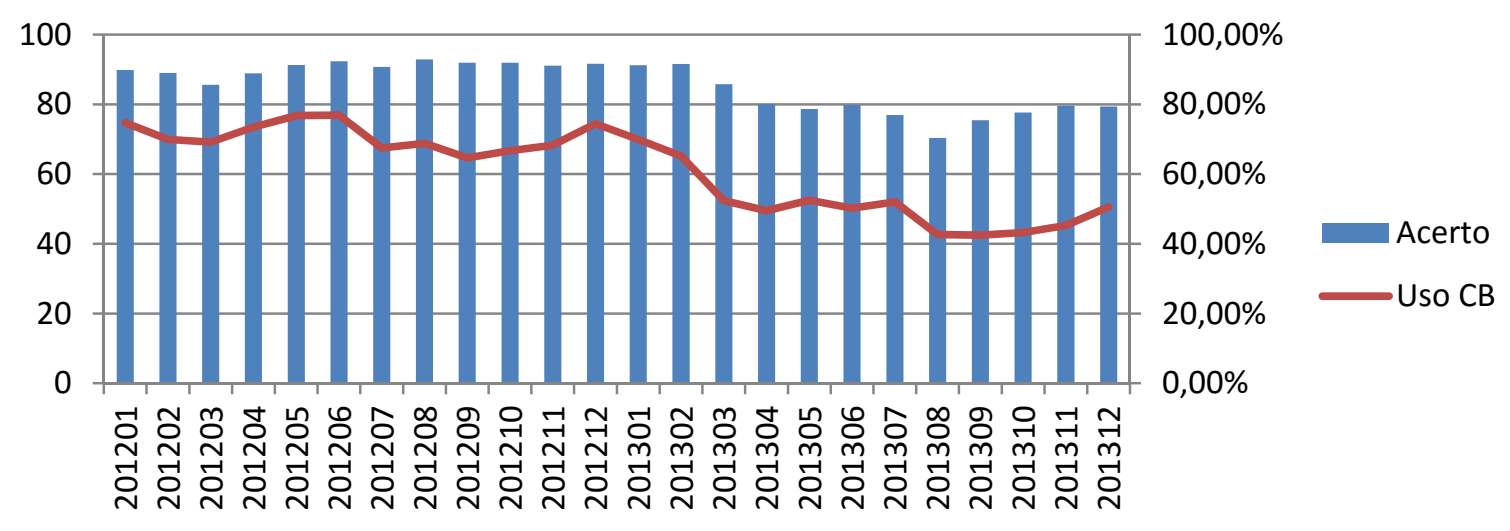

Figura 3. Performance nos anos de 2012 e 2013.

De forma a melhorar a performance e trazê-la de volta a um patamar próximo ao de 2012, foram feitas uma série de modificações entre agosto de 2014 e dezembro de 2015. As melhorias visaram adequar o sistema de resfriamento a nova realidade de laminação focando as modificações na laminação de tiras sem coil box. A Figura 4 exibe o acerto médio das tiras sem coil box, que com a aceleração e o aumento da velocidade máxima das tiras no trem acabador caiu de $86 \%$ para se estabilizar em cerca de $79 \%$ no inicio de 2014.

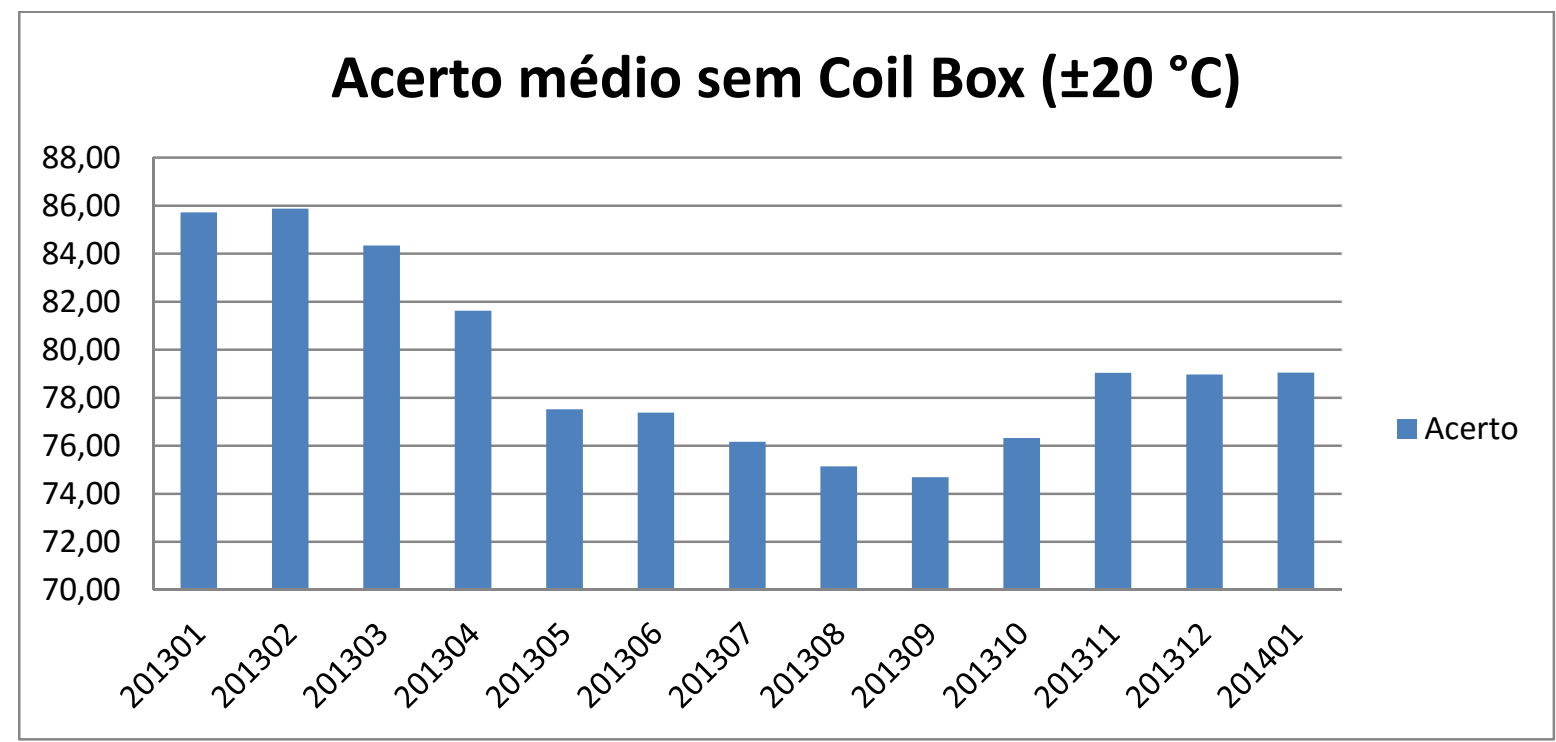

Figura 4. Performance sem coil box.

\section{MELHORIAS IMPLANTADAS E RESULTADOS ALCANÇADOS}

A primeira modificação feita foi em relação ao uso da aceleração pelo modelo matemático de predição. Mesmo tendo um coeficiente que influencie no volume de água graças ao valor da aceleração, à mesma estava sendo considerada zero durante a atualização do modelo em tempo real causando o erro como mostrado na Figura 5. A modificação proposta foi calcular a aceleração do próximo instante de predição baseado na diferença entre a velocidade atual e a velocidade predita de um 
instante à frente, melhorando o acerto durante a fase de aceleração da tira no trem acabador conforme Figura 6. Essa melhoria trouxe um aumento de aproximadamente $2 \%$ (diferença entre 10/2014 e 11/2014 na Figura 7) no acerto médio sem o uso do coil box.

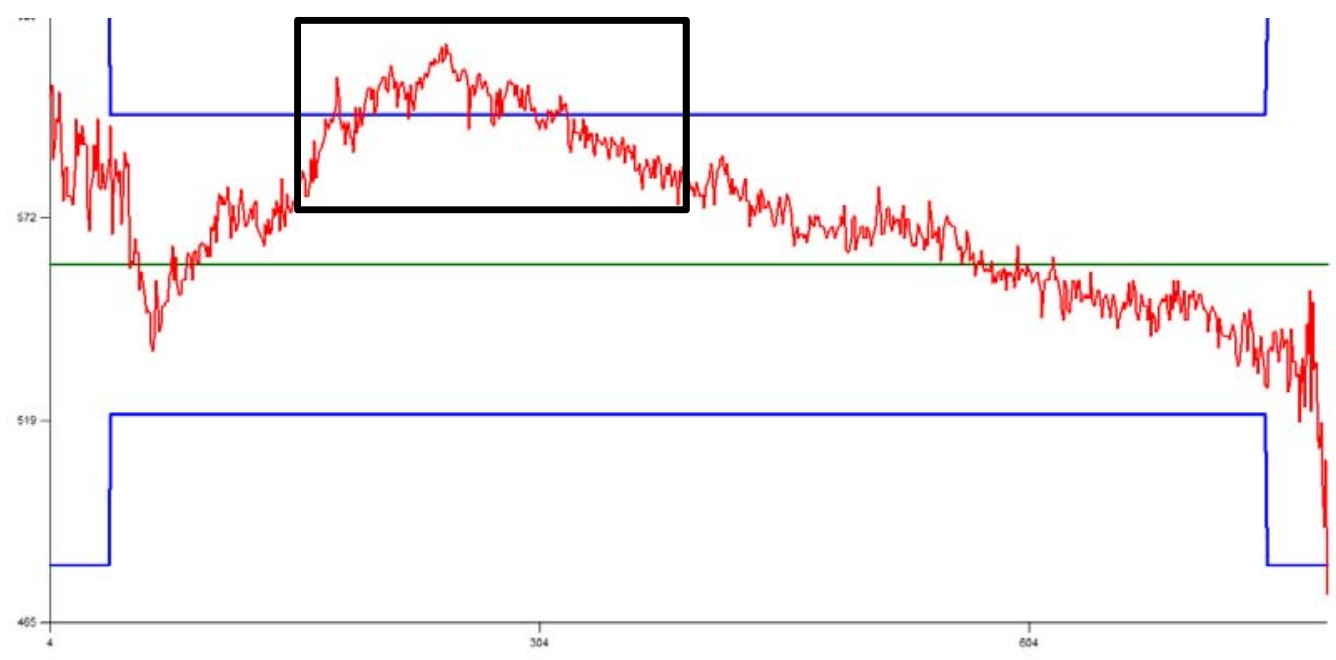

Figura 5. Erro devido a aceleração da tira. A curva vermelha representa a temperatura de bobinamento ao longo do comprimento da tira, e as faixas azuis são os limites definidos pela qualidade.

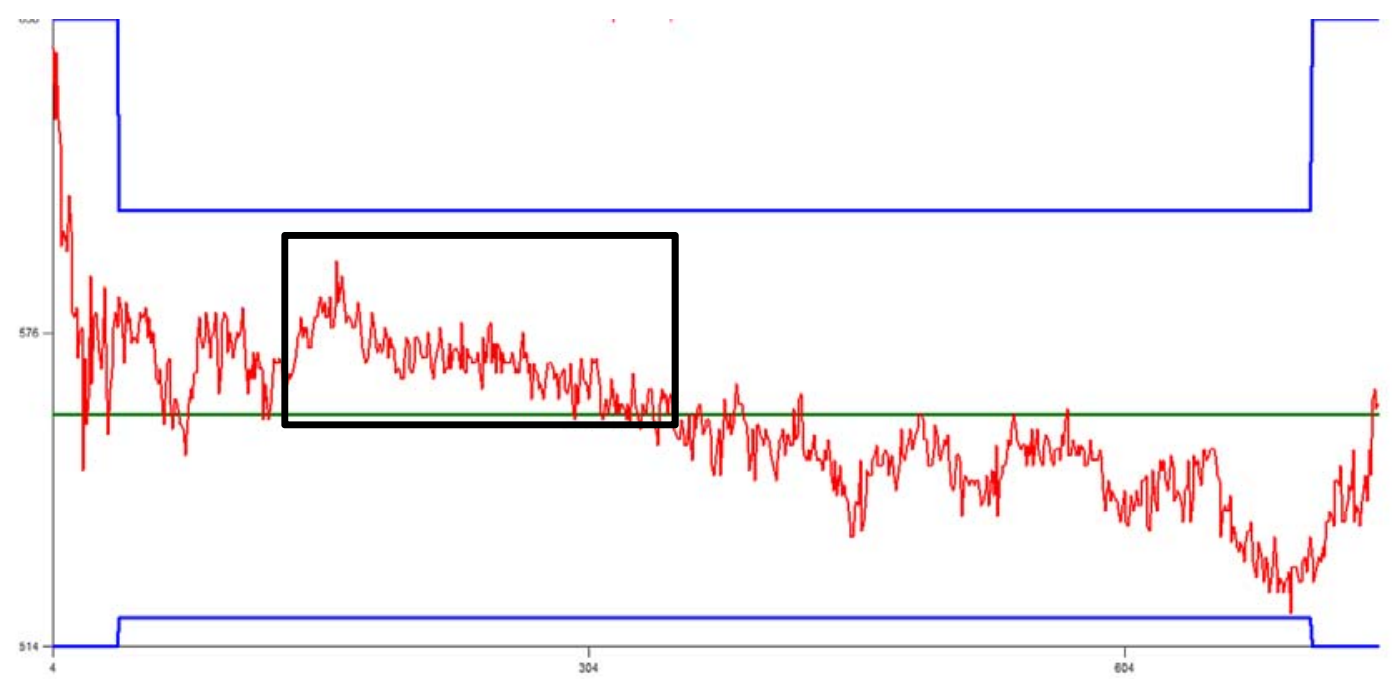

Figura 6. Melhoria do acerto após modificação do modelo em relação ao uso da aceleração. A curva vermelha representa a temperatura de bobinamento ao longo do comprimento da tira, e as faixas azuis são os limites definidos pela qualidade. 


\section{Acerto médio sem Coil Box}

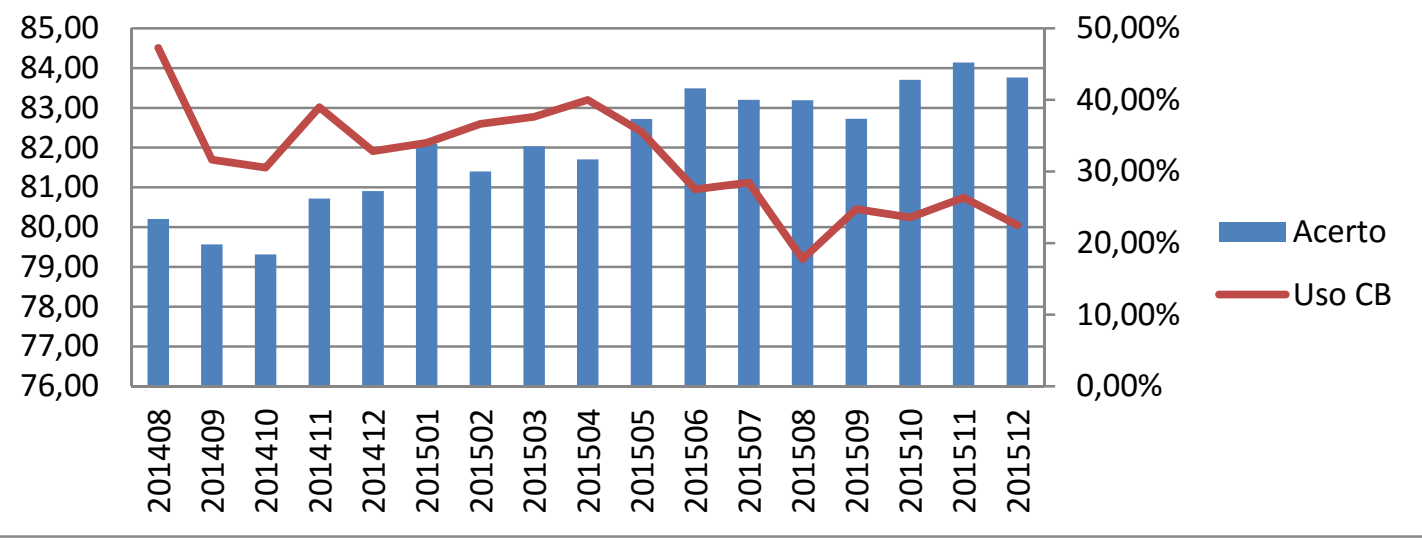

Figura 7. Performance sem coil box.

Com o aumento da velocidade máxima das tiras fez-se necessário o uso da redução de velocidade na cauda ainda dentro do trem acabador (Desaceleração entre os instantes [5] e [6] da Figura 8). Essa mudança no perfil de velocidade fez com que o rastreamento da cauda na mesa de resfriamento ficasse diferente do previsto no modelo original e trouxe a necessidade de modificação (ver Figura 9). A alteração foi antecipar o fechamento dos chuveiros quando estiver próximo ao instante de desaceleração da cauda (ver Figura 10). Com isso foi possível melhorar a performance em cerca de 1 \% (diferença entre 12/2014 e 01/2015 na Figura 5).

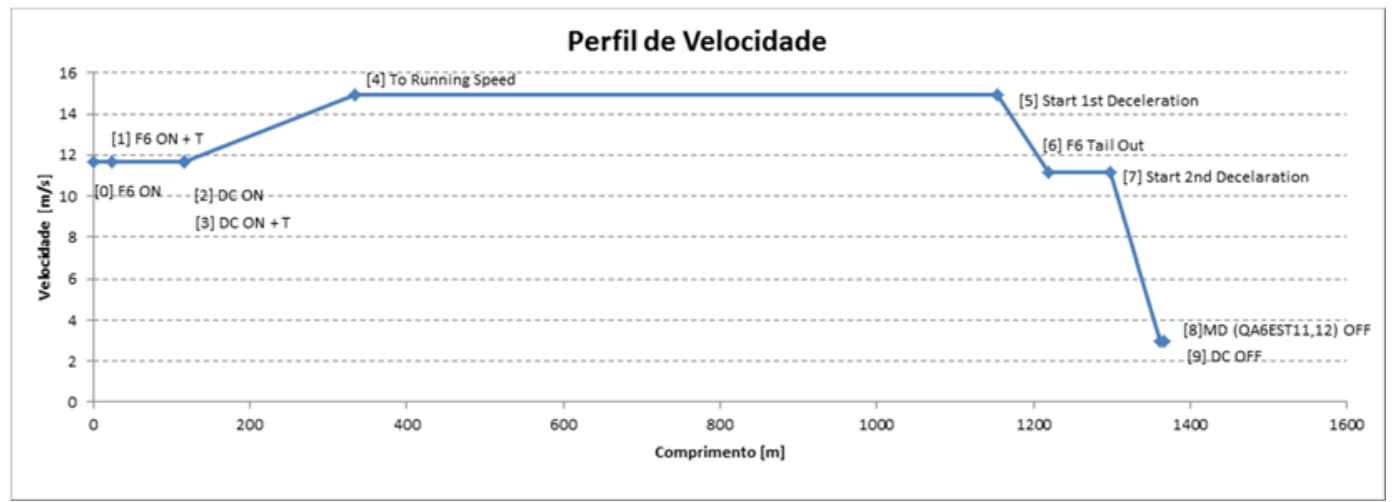

Figura 8. Perfil de velocidade.

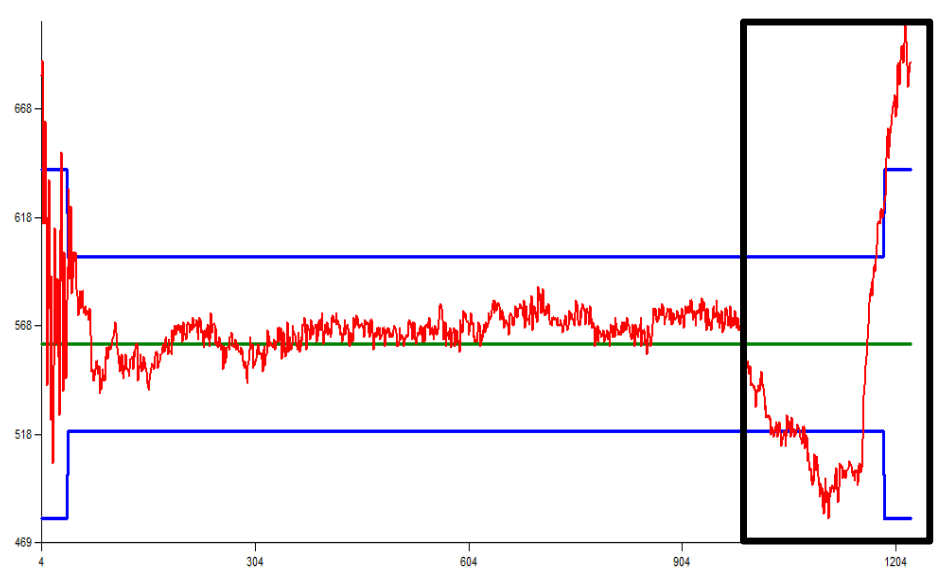

Figura 9. Efeito da desaceleração na cauda. A curva vermelha representa a temperatura de bobinamento ao longo do comprimento da tira, e as faixas azuis são os limites definidos pela qualidade. 


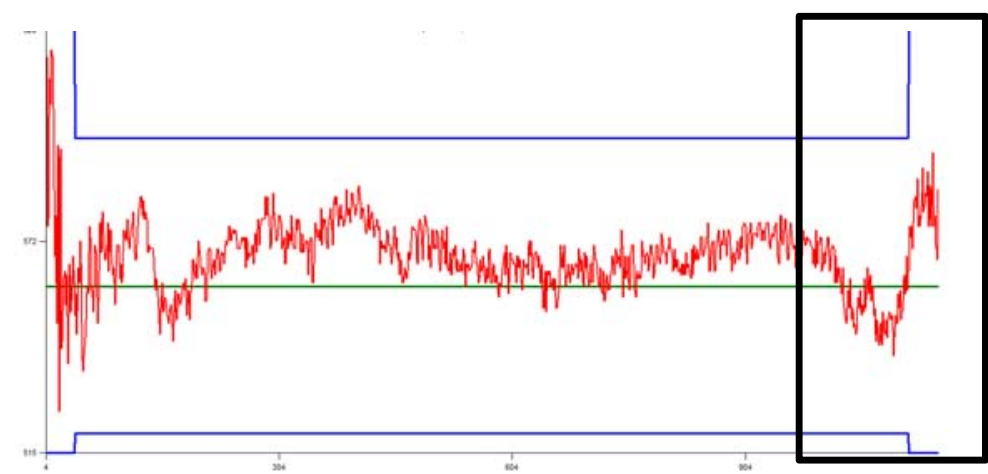

Figura 10. Após correção do rastreamento do ponto de desaceleração na cauda. A curva vermelha representa a temperatura de bobinamento ao longo do comprimento da tira, e as faixas azuis são os limites definidos pela qualidade.

Mesmo melhorando o modelo em relação à aceleração e à desaceleração, a reação às mudanças de velocidade não foram suficientes. A próxima modificação e a mais importante realizada foi a utilização da velocidade real pelo modelo matemático. Originalmente, o sistema se baseava em um perfil de velocidade como o apresentado pela Figura 8. Porém, nem sempre o perfil é seguido em sua totalidade, isso ocasionava um erro muito grande, uma vez que o modelo utilizava uma velocidade predita do perfil enquanto o valor real estava totalmente diferente. $A$ Figura 11 exibe um exemplo de como a velocidade real pode ser diferente da velocidade de perfil, originalmente em um caso como esse a temperatura de bobinamento ficaria como a da Figura 12. Após a implantação do uso da velocidade real no modelo o mesmo passou a prontamente responder alterações de velocidade com o exemplo da Figura 13, onde houve uma diferença entre a velocidade real e a de perfil conforme a Figura 11. Essa modificação possibilitou o incremento de pelo menos $2 \%$ no acerto total em $\pm 20^{\circ} \mathrm{C}$ levando o patamar de acerto sem coil box para aproximadamente $84 \%$ no fim de 2015 .

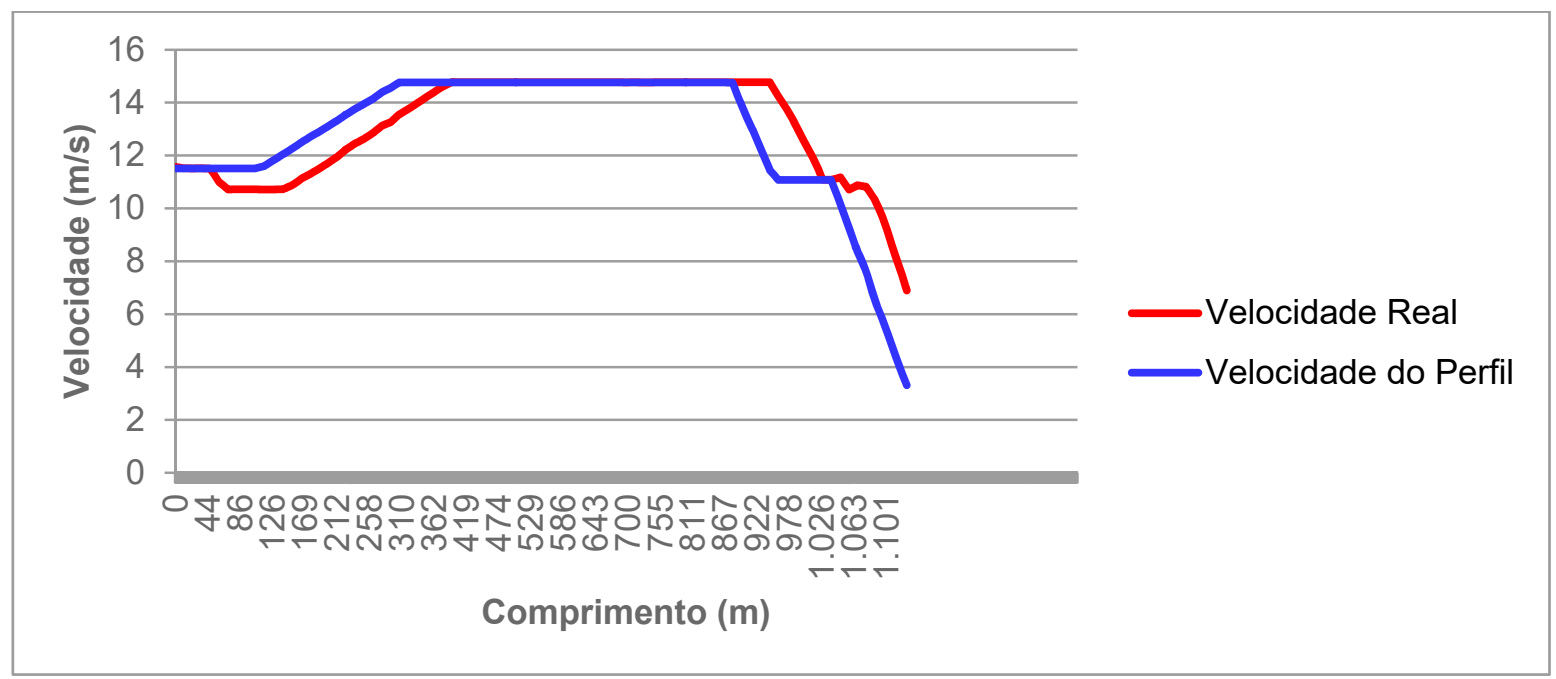

Figura 11. Velocidade Real x Perfil. 


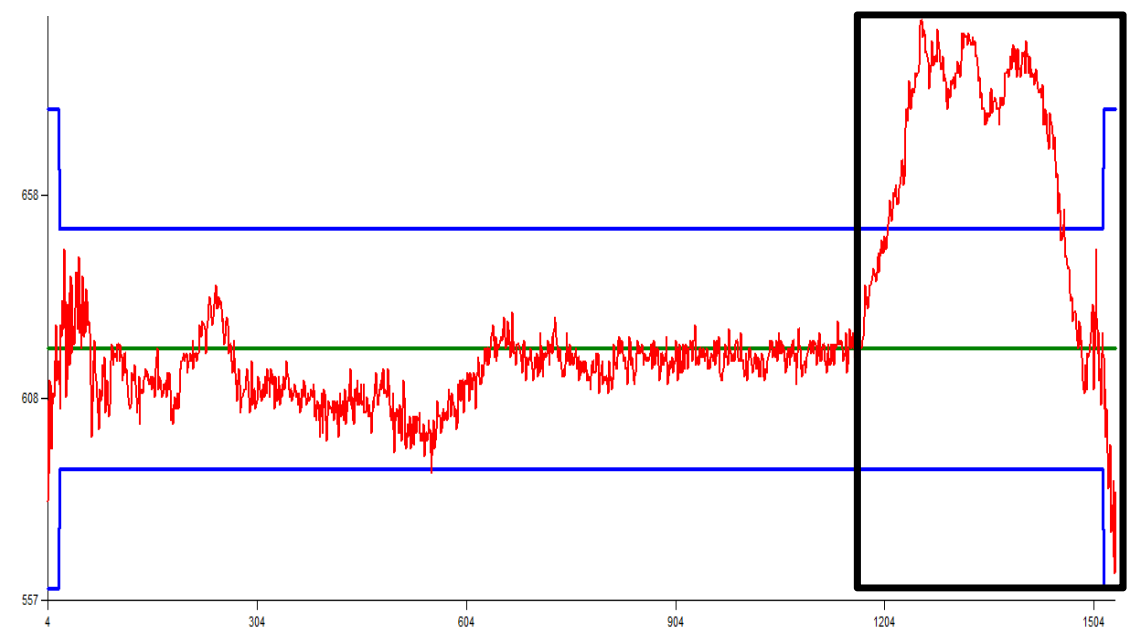

Figura 12. Efeito da diferença de velocidade. A curva vermelha representa a temperatura de bobinamento ao longo do comprimento da tira, e as faixas azuis são os limites definidos pela qualidade.

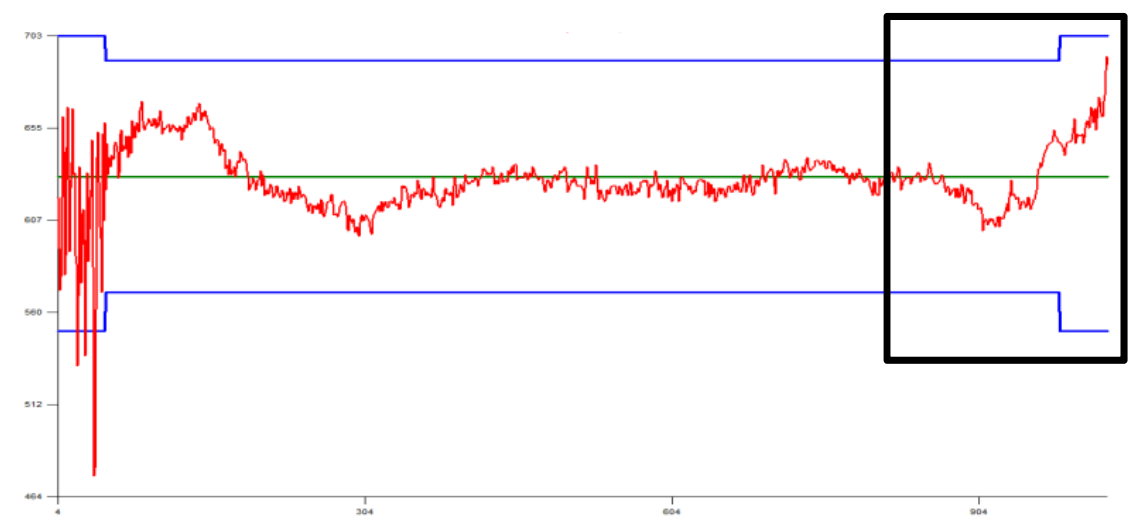

Figura 13. Reação do controle ao uso da velocidade real. A curva vermelha representa a temperatura de bobinamento ao longo do comprimento da tira, e as faixas azuis são os limites definidos pela qualidade.

\section{CONCLUSÃO}

Através das modificações propostas foi possível levar o acerto médio sem coil box de $79 \%$ para $84 \%$ enquanto o uso da mesma foi diminuído até $25 \%$ no fim de 2015 (ver Figura 7). As modificações visaram adaptar o sistema para uma nova realidade de grandes acelerações e desacelerações da tira no trem acabador, uma vez que o mesmo foi projetado e comissionado para uma situação de pouca aceleração e baixas velocidades com uso contínuo de coil box. Alguns desafios permanecem e o objetivo é conseguir levar o acerto para os $90 \%$ em ambos os casos, com e sem coil box. 